\title{
Larvicidal and pupicidal activity of synthesized silver nanoparticles using Leucas aspera leaf extract against mosquito vectors, Aedes aegypti and Anopheles stephensi
}

\author{
S. Sivapriyajothi, P. Mahesh Kumar, K. Kovendan, J. Subramaniam, K. Murugan \\ Department of Zoology, School of Life Sciences, Bharathiar University, Coimbatore, India
}

\begin{abstract}
Mosquitoes are one of the most medically significant groups of vectors, having an ability to transmit parasites and pathogens that can have devastating impacts on humans. The development of reliable and ecofriendly processes for the synthesis of metallic nanoparticles is an important step in the field of application of nanotechnology. In this study, we address the biosynthesis of silver nanoparticles (AgNPs) using Leucas aspera leaf extract, and evaluate its lethal concentration $\left(\mathrm{LC}_{50}\right.$ and $\mathrm{LC}_{90}$ ) values against first to fourth instar larvae and pupae of the mosquito vectors, Aedes aegypti and Anopheles stephensi. The nanoparticles were characterized by UV-Vis spectrum, scanning electron microscopy, energy-dispersive X-ray spectroscopy, and Fourier-transformed infrared spectroscopy analysis. Larvae and pupae were exposed to varying concentrations of aqueous extracts of synthesized AgNPs for $24 \mathrm{~h}$. The maximum mortality was observed from synthesized AgNPs,
\end{abstract}

Correspondence: Kalimuthu Kovendan, Division of Entomology, Department of Zoology, School of Life Sciences, Bharathiar University, Coimbatore 641046, India.

Tel.: +91.9962447932 - Fax: +91.4222422387 .

E-mail: gokulsuryah@gmail.com

Key words: Aedes aegypti, Anopheles stephensi, Leucas aspera, larvicidal activity, silver nanoparticles.

Acknowledgements: the authors are grateful to Mr. N. Muthukrishnan, Technician, and Mr. A. Anbarasan, Lab Assistant, National Centre for Diseases Control (NCDC), Mettupalayam, Tamil Nadu for helping in mosquito sample collection and identifying mosquito species of samples provided for the experiment work.

Received for publication: 2 July 2013.

Revision received: 22 March 2014.

Accepted for publication: 1 April 2014.

(C) Copyright S. Sivapriyajothi et al., 2014

Licensee PAGEPress, Italy

Journal of Entomological and Acarological Research 2014; 46:1787

doi:10.4081/jear.2014.1787

This article is distributed under the terms of the Creative Commons Attribution Noncommercial License (by-nc 3.0) which permits any noncommercial use, distribution, and reproduction in any medium, provided the original author(s) and source are credited. with $\mathrm{LC}_{50}$ values for I-IV instars and pupae ranging from 13.06 to 25.54 , and $\mathrm{LC}_{90}$ values ranging from 24.11 to 47.34 for Ae. aegypti; for $A n$. stephensi, the corresponding $\mathrm{LC}_{50}$ values ranged from 12.45 to 22.26 , and the $\mathrm{LC}_{90}$ values ranged from 23.50 to 42.95 . With methanol leaf extract of L. aspera against Ae. aegypti, the $\mathrm{LC}_{50}$ values ranged from 174.89 to 462.96 and the $\mathrm{LC}_{90}$ values ranged from 488.16 to 963.74 ; for An. stephen$s i$, the corresponding $\mathrm{LC}_{50}$ values ranged from 148.93 to 417.07 and the $\mathrm{LC}_{90}$ values ranged from 449.72 to 912.94 . The study suggests that nanoparticles could be a preferred alternative to the most hazardous existing chemical pesticides, contributing to a more healthy environment by providing an ideal ecological and user-friendly vector control strategy for managing malaria and dengue, and contributing to their eventual elimination in the near future.

\section{Introduction}

Mosquitoes are the principal vectors of many vector-borne diseases affecting human beings and animals, in addition to being nuisance pests. Vector-borne diseases in India, e.g., malaria, dengue, chikungunya, filariasis, Japanese encephalitis, and leishmaniasis, cause thousands of deaths per year. India reports 1.48 million malarial cases and about 1173 deaths, 1.4 million suspected and 1985 confirmed chikungunya cases, 5000 Japanese encephalitis cases and approximately 1000 deaths, and 383 dengue cases and 6 deaths during 2006 and 2007 (Kumar et al., 2007; WHO, 2007; Gopalan \& Das, 2009; Dhiman et al., 2010). Malaria infects more than 500 million people each year, killing approximately 1.2 to 2.7 million annually. Among the 109 malaria endemic countries, India had 1.5 million confirmed malaria cases in 2009 with over 1000 deaths (WHO, 2010). Anopheles stephensi is the primary vector of malaria in India and other West Asian countries, and improved methods of control are urgently needed (Burfield \& Reekie, 2005; Mittal et al., 2005). Malaria, caused by Plasmodium falciparum, is one of the leading causes of human morbidity and mortality from infectious diseases, predominantly in tropical and subtropical countries (Snow et al., 2005). The highest number of malaria ( $P$. falciparum) cases and malaria-related deaths are recorded from the state of Orissa located in the eastern part of India (Sharma et al., 2010).

Dengue fever/dengue hemorrhagic fever (DHF) continues to be of major public health importance in countries of the Western Pacific and Southeast Asia. These regions are experiencing an increase in the frequency of epidemics. Since 1963, outbreaks of dengue/DHF have been recorded in almost all parts of India. The increasing trend of dengue outbreaks accompanied by DHF is posing a problem of utmost importance to the public health of India (WHO, 1999). Botanical and microbial insecticides have been increasingly used for mosquito control 
because of their efficacy and documented non-toxic effects on non-target organisms (Ascher et al., 1995).

Biosynthesis of nanoparticles using plant extracts is currently under development. Use of plants for the synthesis of nanoparticles could be advantageous over other environmentally benign biological processes, as this eliminates the elaborate process of maintaining cell cultures. Biosynthetic processes for nanoparticles would be more useful if nanoparticles were produced extracellularly using plants or their extracts in a controlled manner according to their size, shape and disparity (Kumar \& Yadav, 2009). In recent years, plant-mediated biological synthesis of nanoparticles has gained importance due to its simplicity and eco-friendliness.

The plant, Leucas aspera Wild., a member of the Lamiaceae family and commonly known as Thumbai, is distributed throughout India. It is pungently aromatic and commonly used as an antipyretic herb in South India. The juices from the leaves are used as an external application for psoriasis and painful swelling. The flowers are used with honey to treat coughs and cold in children. The leaves are useful for the treatment of chronic rheumatism. Crushed leaves are applied to the bites of snakes, poisonous insects, and scorpion stings (Srinivasan et al., 2011). The plant is used traditionally as an antipyretic and its insecticidal flowers are valued as a stimulant, diaphoretic, insecticide and emmenagogue. Leaves are considered useful in chronic rheumatism, psoriasis and other chronic skin eruptions. L. aspera leaves are used as an insecticide and mosquito repellent in rural areas (Sadhu et al., 2003; Maheswaran et al., 2008). Many researchers have reported on the effectiveness of plant extracts against mosquito larvae (Govindarajan et al., 2008; Kovendan et al., 2012b, 2012c, 2012d). In the present study, to evaluate the larvicidal and pupicidal activity of AgNPs synthesized using $L$. aspera, leaf extract was assessed under laboratory conditions against the target species of An. stephensi and Ae. aegypti.

\section{Materials and methods}

\section{Collection of plants and preparation of extracts}

L. aspera plants were collected from in and around Bharathiar University Campus, Coimbatore. L. aspera leaves were washed with tap water and shade-dried at room temperature $\left(28 \pm 2^{\circ} \mathrm{C}\right)$ for 5 to 10 days. The air-dried leaves were powdered using an electric blender; $500 \mathrm{~g}$ of the powder was gradually macerated in $1.5 \mathrm{~L}$ of methanol over a period of $72 \mathrm{~h}$ and filtered. The total yield of the $L$. aspera crude extract using the methanol extraction method was $13.6 \mathrm{~g}$. The extracts were concentrated at a reduced temperature on a rotary vacuum evaporator and stored at $4^{\circ} \mathrm{C}$. One gram of the plant residue was dissolved in $100 \mathrm{~mL}$ of acetone, which was considered a $1 \%$ stock solution. From this stock solution we prepared various concentrations (50, 150, 250, 350 and 450 ppm). $\mathrm{AgNO}_{3}$ was purchased from the Precision Scientific Company (Pvt Ltd., Coimbatore, Tamil Nadu, India).

\section{Synthesis of silver nanoparticles}

Leaves were washed with distilled water and dried for $3 \mathrm{~d}$ at room temperature. A plant leaf broth was prepared by placing $10 \mathrm{~g}$ of the leaves (finely cut) in a $300 \mathrm{~mL}$ flask with $100 \mathrm{~mL}$ of sterile distilled water. This mixture was boiled for $5 \mathrm{~min}$, decanted, stored at $-4^{\circ} \mathrm{C}$, and used in our tests within 1 week. The filtrate was treated with aqueous $1 \mathrm{mM} \mathrm{AgNO}{ }_{3}$ solution in an Erlenmeyer flask and incubated at room temperature. As a result, formation of a brown-yellow solution, indicating the formation of AgNPs, it was found that aqueous silver ions can be reduced by an aqueous extract of plant parts to generate extremely stable silver nanoparticles in water.

\section{Characterisation of silver nanoparticles}

Presence of synthesized silver nanoparticles was confirmed by sampling the reaction mixture at regular intervals, and the absorption maxima was scanned by UV-Vis spectra, at a wavelength of $200-700 \mathrm{~nm}$ using a UV-3600 Shimadzu spectrophotometer at $1 \mathrm{~nm}$ resolution. The reaction mixture was then centrifuged at 15,000 rpm for $20 \mathrm{~min}$, and the resulting pellet was dissolved in deionized water and filtered through a Millipore filter $(0.45 \mu \mathrm{m})$. An aliquot of this filtrate containing silver nanoparticles was used for scanning electron microscopy (SEM), energy dispersive X-ray spectroscopy (EDS) and Fourier transformed infra red spectroscopic (FTIR) studies. The structure and composition of freeze-dried purified silver particles was analysed by using a $10 \mathrm{kV}$ ultra high resolution scanning electron microscope; $25 \mu \mathrm{L}$ of the sample was spatter-coated on a copper stub and the images of nanoparticles were studied using FEI QUANTA-200 SEM. The surface groups of the nanoparticles were qualitatively confirmed by using FTIR spectroscopy (Stuart, 2002), with spectra recorded by a Perkin-Elmer Spectrum 2000 FTIR spectrophotometer. In addition, the presence of metals in the sample was analysed by EDS.

\section{Mosquito culture}

An. stephensi and Ae. aegypti eggs were collected from the National Centre for Disease Control field station Mettupalayam, Tamil Nadu, using an $O$ type brush. These eggs were brought to the laboratory and transferred to $18 \times 13 \times 4 \mathrm{~cm}$ enamel trays containing $500 \mathrm{~mL}$ of water for hatching. The mosquito larvae were fed pedigree dog biscuits and yeast in a 3:1 mixture. The feeding was continued until the larvae developed to the pupal stage. The pupae were collected from the culture trays and transferred to plastic containers $(12 \times 12 \mathrm{~cm})$ containing $500 \mathrm{~mL}$ of water using a dipper. The plastic jars were kept in a $90 \times 90 \times 90-\mathrm{cm}$ mosquito cage for adult emergence. Mosquito larvae were maintained at $27+2^{\circ} \mathrm{C}, 75-85 \%$ relative humidity, under a photoperiod of $14: 10$ (light/dark). A 10\% sugar solution was provided for a period of 3 days before blood feeding. The adult female mosquitoes were allowed to feed on the blood of a rabbit (one rabbit per day, exposed on the dorsal side) for 2 days, to ensure adequate blood feeding for 5 days. After blood feeding, enamel trays with water from the culture trays were placed in the cage as oviposition substrates.

\section{Larval and pupal toxicity test}

The larvicidal activity was assessed by the procedure of WHO (1999) with some slight modification and as per the method of Kovendan et al. (2012a). Twenty-five specimens of first to fourth instar larvae and pupae were introduced into a 500 -mL glass beaker containing $249 \mathrm{~mL}$ of dechlorinated water, and $1 \mathrm{~mL}$ of the desired concentrations of leaf extract and synthesized silver nanoparticles (10, 15, 20, 25 and $30 \mathrm{ppm}$ ) were added. Larval food was provided also for the test larvae. At each tested concentration, two to five trials were conducted and each trial consisted of five replicates. The control was set up by mixing $1 \mathrm{~mL}$ of acetone with $249 \mathrm{~mL}$ of dechlorinated water. The larvae and pupae were exposed to dechlorinated water without acetone, which served as a control. The control mortalities were corrected by using Abbott's formula (Abbott, 1925).

Corrected mortality $=$

Observed mortality in treatment-Observed mortality in control $\times 100$

100-Control mortality

Percentage mortality $=$

Number of dead larvae/pupae $\times 100$ 


\section{Statistical analysis}

The average larval and pupal mortality data were subjected to probit analysis for calculating the $\mathrm{LC}_{50}, \mathrm{LC}_{90}$, and other statistics at the $95 \%$ upper and lower fiducidal limits, and Chi-square values were calculated by using the method of Finney (1971). The statistical software package SPSS (2007) version 16.0 was used. Results with $\mathrm{P}<0.05$ were considered to be statistically significant.

\section{Results and discussion}

The results of the larvicidal and pupicidal mortality caused by leaf extracts of $L$. aspera and synthesized AgNPs against Ae. aegypti and An. stephensi are presented in Tables 1-4 and Figures 1 and 2 . The $\mathrm{LC}_{50}$ and $\mathrm{LC}_{90}$ values of $L$. aspera and synthesized AgNPs against first to fourth instars larvae and pupae of An. stephensi and Ae. aegypti can be summarized as follows: the $\mathrm{LC}_{50}$ values of the methanol extracts of $L$. aspera against instars I-IV and pupae of Ae. aegypti ranged from 174.89 to 462.96, and the $\mathrm{LC}_{90}$ values ranged from 488.16 to 963.74 ; for $A n$. stephensi, the $\mathrm{LC}_{50}$ and $\mathrm{LC}_{90}$ values ranged from 148.93 to 417.07 and 449.72 to 912.94 , respectively. The corresponding $\mathrm{LC}_{50}$ and $\mathrm{LC}_{90}$ values of the synthesized AgNPs against Ae. aegypti ranged from 13.06 to 25.54 and 24.11 to 47.34 , respectively; against $A n$. stephensi, the $\mathrm{LC}_{50}$ and $\mathrm{LC}_{90}$ values ranged from 12.45 to 22.26 and 23.50 to 42.95 , respectively.

All the larvae and pupae tested showed evidence of a lethal effect, and mortality was positively dose-dependent against mosquito vectors, An. stephensi and Ae. aegypti.

Larvicides play a vital role in controlling mosquitoes in their breeding sites. The present study was carried out to establish the larvicidal activities of biosynthesized silver nanoparticles (AgNPs) against $A n$. stephensi responsible for diseases of public health importance. The use of natural product chemistry coupled with nanotechnology that reduces mosquito populations in the larval stage can provide many associated benefits to vector control. Since silver nanoparticles are considered to be potential agents for various biological applications including antimicrobials, their application as a mosquito larvicide was investigated. Plants are rich sources of bioactive compounds that can be used to develop environmentally safe vector and pest control agents. The botanical extracts from the plant leaves, roots, seeds, flowers and bark in their crude form have been used as conventional insecticides for centuries. Today, the environmental safety of an insecticide is considered to be of paramount importance. An insecticide does not have to cause high mortality to target organisms to be effective (Kabaru \& Gichia, 2001).

The potential uses and benefits of nanotechnology are numerous.

Table 1. Larval and pupal toxicity effect of Leucas aspera methanol leaf extract against malaria vector, Anopheles stephensi.

\begin{tabular}{|c|c|c|c|c|c|c|c|c|}
\hline $\begin{array}{l}\text { Mosquito } \\
\text { life stages }\end{array}$ & 50 & $\begin{array}{c}\text { Concen } \\
150\end{array}$ & $\begin{array}{c}\text { rval and } \\
\text { ion of } L \text {. } \\
250\end{array}$ & $\begin{array}{l}\text { mortalit } \\
\text { (ppm) } \\
350\end{array}$ & 450 & $\begin{array}{l}\mathrm{LC}_{50}(\mathrm{ppm}) \\
\text { (LFL-UFL) }\end{array}$ & $\begin{array}{l}\mathrm{LC}_{90}(\mathrm{ppm}) \\
\text { (LFL-UFL) }\end{array}$ & $\begin{array}{c}x^{2} \\
(d f=4)\end{array}$ \\
\hline I instar & $36 \pm 0.81$ & $49.1 \pm 0.65$ & $65.1 \pm 0.18$ & $77.6 \pm 0.47$ & $92.8 \pm 0.58$ & $\begin{array}{c}148.93 \\
(111.96-178.75)\end{array}$ & $\begin{array}{c}449.72 \\
(402.39-518.49)\end{array}$ & $1.76^{\mathrm{a}}$ \\
\hline II instar & $31.3 \pm 0.94$ & $41 \pm 0.52$ & $59.6 \pm 1.24$ & $67.3 \pm 0.47$ & $81.6 \pm 2.05$ & $\begin{array}{c}199.44 \\
(160.57-232.97)\end{array}$ & $\begin{array}{c}571.90 \\
(500.32-685.50)\end{array}$ & $0.90^{\mathrm{a}}$ \\
\hline III instar & $28.3 \pm 1.95$ & $35.1 \pm 0.83$ & $52.3 \pm 0.94$ & $60.1 \pm 0.62$ & $72.6 \pm 1.69$ & $\begin{array}{c}252.88 \\
(213.64-292.55)\end{array}$ & $\begin{array}{c}681.44 \\
(582.66-850.45)\end{array}$ & $0.75^{\mathrm{a}}$ \\
\hline IV instar & $23.7 \pm 0.52$ & $29.3 \pm 1.24$ & $43.9 \pm 0.77$ & $50.9 \pm 0.89$ & $57.7 \pm 1.79$ & $\begin{array}{c}349.99 \\
(300.35-423.80)\end{array}$ & $\begin{array}{c}888.00 \\
(722.54-1219.62)\end{array}$ & $0.8^{\mathrm{a}}$ \\
\hline Pupa & $17 \pm 1.41$ & $23.2 \pm 2.44$ & $35.1 \pm 1.89$ & $44.2 \pm 2.05$ & $52.1 \pm 1.32$ & $\begin{array}{c}417.07 \\
(362.34-507.41)\end{array}$ & $\begin{array}{c}912.94 \\
(749.58-1228.95)\end{array}$ & $0.36^{\mathrm{a}}$ \\
\hline
\end{tabular}

Control nil mortality; SD, standard deviation; $\mathrm{LC}_{50}, 50 \%$ lethal concentration; LFL, lower fiducial limit; UFL, upper fiducial limit; $\mathrm{LC}_{90}, 90 \%$ lethal concentration; $\chi^{2}$, chi-square value; $d f$, degrees of freedom. *Each mean \pm SD value is of five replicates. ${ }^{\mathrm{a}}<0.05$, significance level.

Table 2. Larval and pupal toxicity effect of Leucas aspera methanol leaf extract against dengue vector, Aedes aegypti.

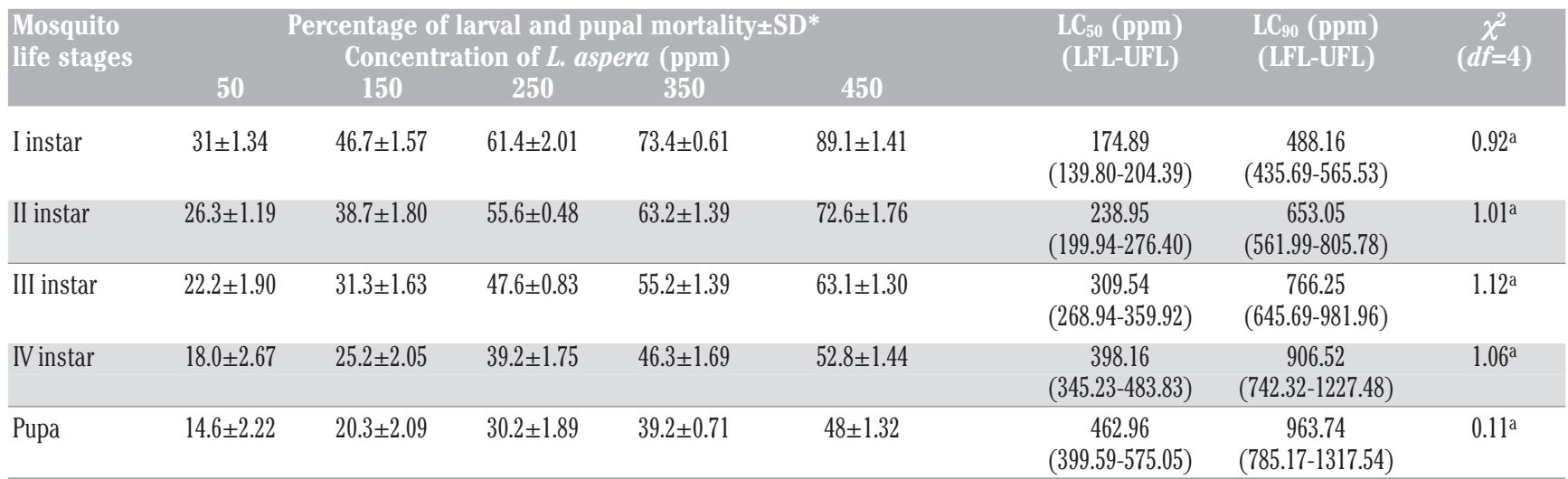

Control nil mortality; SD, standard deviation; $\mathrm{LC}_{50}, 50 \%$ lethal concentration; $\mathrm{LFL}$, lower fiducial limit; UFL, upper fiducial limit; $\mathrm{LC}_{90}, 90 \%$ lethal concentration; $\chi^{2}$, chi-square value; $d f$, degrees of freedom. *Each mean \pm SD value is of five replicates. ${ }^{\mathrm{a}}<0.05$, significance level. 
These include agricultural productivity enhancement involving nanoporous zeolites for slow release and efficient dosage of water and fertilizer, nanocapsules for herbicide delivery, vector and pest management, and nanosensors for pest detection (Scrinis \& Lyons, 2007; Scott, 2007; Joseph \& Morrison, 2006; Liu \& Du, 2004). The utilization of biological systems for nanoparticle synthesis is a notable alternative for the advancement of this multifaceted approach. Biological systems have shown the ability to interact with metal ions and reduce them to form metallic nanoparticles (Beveridge et al., 1997). Plants are widely used for nanoparticle synthesis, and the use of plants for the fabrication of nanoparticles is a rapid, low-cost, eco-friendly single step method for the biosynthesis process (Huang et al., 2007).

The colour intensity of the leaf extracts of $L$. aspera incubated with silver ions at the beginning of the reaction and after $2 \mathrm{~h}$ of reaction is shown in Figure 3A. AgNPs were observed to be stable in solution and show very little aggregation. The appearance of the yellowish brown colour was an indication of formation of colloidal silver nanoparticles in the medium. The brown colour could be due to the excitation of surface plasmon vibrations, typical of the silver nanoparticles (Ahmad et al., 2003; Krishnaraj et al., 2010). It is generally recognized that UV-Vis spectroscopy can be used to examine size and shape-controlled nanoparticles in aqueous suspensions (Shrivastava \& Dash, 2010). Figure 3B displays the UV-Vis spectra of the leaf solution as a function of reaction time. The strong resonance centred at $400 \mathrm{~nm}$ was clearly observed and increased in intensity with time, and could arise from the excitation of longitudinal Plasmon vibrations in silver NPs in the solution. These changes have been attributed to the excitation of surface plasmon resonance in the metal nanoparticles (Natarajan et al., 2010). Reduction of silver ions present in the aqueous solution of silver complex during the reaction with the ingredients present in the leaves of $L$. aspera extract observed by the UV-Vis spectroscopy revealed that the presence of silver nanoparticles may be correlated with the UV-Vis spectra.

For the SEM studies, reaction mixtures were air-dried on silicon wafers. As a result, a coffee-ring phenomenon was observed. It is well known that when liquids that contain fine particles are evaporated on a flat surface, the particles accumulate along the outer edge and form typical structures (Chen \& Evans, 2009). A representative SEM micrograph (Figure 4A) of synthesized nanoparticles shows spherical and cubic structures with a size range of $30-37 \mathrm{~nm}$. The rough morphology of the AgNPs provides excellent larvicidal activity of the synthesized nanoparticles. In addition, the capped silver particles were stable in solution for at least 8 weeks. The EDS attachment of the SEM can provide information on the chemical analysis of the fields being investigated or the composition at specific locations (spot EDS). Figure 4B shows a representative profile of the spot EDS analysis, obtained by focusing on AgNPs. The silver nanoparticles formed were predominant-

Table 3. Larval and pupal toxicity effect of synthesized AgNPs against malaria vector, Anopheles stephensi.

\begin{tabular}{|c|c|c|c|c|c|c|c|c|}
\hline $\begin{array}{l}\text { Mosquito } \\
\text { life stages }\end{array}$ & 10 & $\begin{array}{c}\text { centage } \\
\text { Concen } \\
15\end{array}$ & $\begin{array}{l}\text { Irval and } \\
\text { ion of AgI } \\
20\end{array}$ & $\begin{array}{l}\text { al mortali } \\
\text { (ppm) } \\
25\end{array}$ & 30 & $\begin{array}{c}\mathrm{LC}_{50}(\mathrm{ppm}) \\
\text { (LFL-UFL) }\end{array}$ & $\begin{array}{c}\text { LC }_{90}(\mathrm{ppm}) \\
\text { (LFL-UFL) }\end{array}$ & $\begin{array}{c}x^{2} \\
(d f=4)\end{array}$ \\
\hline I instar & $41.2 \pm 2.62$ & $60.2 \pm 1.22$ & $79.8 \pm 1.71$ & $90.4 \pm 1.38$ & $100.0 \pm 0.0$ & $\begin{array}{c}12.45 \\
(10.80-13.76)\end{array}$ & $\begin{array}{c}23.50 \\
(21.96-25.56)\end{array}$ & $3.34^{\mathrm{a}}$ \\
\hline II instar & $35.2 \pm 1.15$ & $49.2 \pm 1.37$ & $63.1 \pm 2.27$ & $81.2 \pm 1.22$ & $96.2 \pm 0.0$ & $\begin{array}{c}15.01 \\
(13.40-16.35)\end{array}$ & $\begin{array}{c}28.37 \\
(26.34-31.21)\end{array}$ & $3.98^{\mathrm{a}}$ \\
\hline III instar & $32.6 \pm 1.71$ & $43.0 \pm 1.82$ & $56.6 \pm 1.30$ & $76.4 \pm 0.82$ & $89.4 \pm 1.22$ & $\begin{array}{c}16.55 \\
(14.89-17.98)\end{array}$ & $\begin{array}{c}31.77 \\
(29.22-35.49)\end{array}$ & $2.18^{\mathrm{a}}$ \\
\hline IV instar & $26.8 \pm 1.25$ & $39.4 \pm 1.32$ & $48.8 \pm 1.70$ & $65.4 \pm 1.10$ & $79.7 \pm 1.70$ & $\begin{array}{c}19.17 \\
(17.46-20.81)\end{array}$ & $\begin{array}{c}37.23 \\
(33.59-42.95)\end{array}$ & $0.81^{\mathrm{a}}$ \\
\hline Pupa & $21.5 \pm 1.10$ & $34.2 \pm 1.18$ & $45.4 \pm 1.85$ & $53.8 \pm 1.20$ & $69.7 \pm 0.55$ & $\begin{array}{c}22.26 \\
(20.42-24.40)\end{array}$ & $\begin{array}{c}42.95 \\
(37.89-51.50)\end{array}$ & $0.62^{\mathrm{a}}$ \\
\hline
\end{tabular}

Control nil mortality; SD, standard deviation; $\mathrm{LC}_{50}, 50 \%$ lethal concentration; $\mathrm{LFL}$, lower fiducial limit; UFL, upper fiducial limit; $\mathrm{LC}_{90}, 90 \%$ lethal concentration; $\chi^{2}$, chi-square value; $d f$, degrees of freedom. *Each mean \pm SD value is of five replicates. ${ }^{\mathrm{P}}<0.05$, significance level.

Table 4. Larval and pupal toxicity effect of synthesized AgNPs against dengue vector, Aedes aegypti.

\begin{tabular}{|c|c|c|c|c|c|c|c|c|}
\hline $\begin{array}{l}\text { Mosquito } \\
\text { life stages }\end{array}$ & 10 & $\begin{array}{c}\text { centage } 0 \\
\text { Concent } \\
15\end{array}$ & $\begin{array}{l}\text { Irval and } \\
\text { ion of AgI } \\
20\end{array}$ & $\begin{array}{l}\text { I mortali } \\
\text { (ppm) } \\
25\end{array}$ & 30 & $\begin{array}{l}\mathrm{LC}_{50}(\mathrm{ppm}) \\
\text { (LFL-UFL) }\end{array}$ & $\begin{array}{c}\mathrm{LC}_{90}(\mathrm{ppm}) \\
\text { (LFL-UFL) }\end{array}$ & $\begin{array}{c}x^{2} \\
(d f=4)\end{array}$ \\
\hline I instar & $39.2 \pm 1.62$ & $57.2 \pm 0.80$ & $76.8 \pm 1.25$ & $89.4 \pm 1.38$ & $100 \pm 0.0$ & $\begin{array}{c}13.06 \\
(11.50-14.32)\end{array}$ & $\begin{array}{c}24.11 \\
(22.56-26.21)\end{array}$ & $4.02^{\mathrm{a}}$ \\
\hline II instar & $33.2 \pm 2.05$ & $48.8 \pm 1.90$ & $61.2 \pm 1.87$ & $72 \pm 1.72$ & $88.0 \pm 1.10$ & $\begin{array}{c}15.88 \\
(13.90-17.48)\end{array}$ & $\begin{array}{c}32.92 \\
(29.98-37.41)\end{array}$ & $1.20^{\mathrm{a}}$ \\
\hline III instar & $29.6 \pm 1.47$ & $37.4 \pm 1.75$ & $54.9 \pm 1.80$ & $64.2 \pm 0.59$ & $82.2 \pm 1.21$ & $\begin{array}{c}18.52 \\
(16.77-20.14)\end{array}$ & $\begin{array}{c}36.47 \\
(32.95-41.98)\end{array}$ & $1.70^{\mathrm{a}}$ \\
\hline IV instar & $20.8 \pm 0.90$ & $31.4 \pm 1.63$ & $46.8 \pm 1.90$ & $54.4 \pm 1.10$ & $71.4 \pm 1.30$ & $\begin{array}{c}22.10 \\
(20.39-24.06)\end{array}$ & $\begin{array}{c}41.28 \\
(36.81-48.55)\end{array}$ & $0.75^{\mathrm{a}}$ \\
\hline Pupa & $18.5 \pm 1.60$ & $26.2 \pm 2.11$ & $37.4 \pm 1.35$ & $48.2 \pm 1.50$ & $60.8 \pm 0.55$ & $\begin{array}{c}25.54 \\
(23.42-28.51)\end{array}$ & $\begin{array}{c}47.34 \\
(41.18-58.20)\end{array}$ & $0.05^{\mathrm{a}}$ \\
\hline
\end{tabular}

Control nil mortality; SD, standard deviation; $\mathrm{LC}_{50}, 50 \%$ lethal concentration; LFL, lower fiducial limit; UFL, upper fiducial limit; $\mathrm{LC}_{90}, 90 \%$ lethal concentration; $\chi^{2}$, chi-square value; $d f$, degrees of freedom. *Each mean \pm SD value is of five replicates. ${ }^{\text {P }}<0.05$, significance level. 
ly cubical with a uniform shape. It is known that the shape of metal nanoparticles considerably changes their optical and electronic properties (Xu \& Käll, 2002). The particle shape of plant-mediated AgNPs are mostly spherical, with the exception of neem (Azadirachta indica), which yields poly-dispersed particles with both spherical and flat platelike morphology, 5-35 nm in size (Shankar et al., 2004). The overall morphology of AgNPs is more clearly seen, and the particles are monodispersed, having circular and flower shapes, respectively. Strong signals from the silver atoms in the nanoparticles were observed, and signals from $\mathrm{Si}, \mathrm{K}, \mathrm{C}$, and $\mathrm{Pt}$ atoms were also recorded. The $\mathrm{C}$ and $\mathrm{K}$ signals were likely due to X-ray emission from carbohydrates, proteins, and enzymes present in the cell wall of the biomass.

The FTIR spectra of aqueous silver nanoparticles prepared from the L. aspera leaf extract (Figure 5) show transmittance peaks. Further, the results of the FTIR values of synthesized silver nanoparticles showed the presence of various functional groups such as alkane groups, methylene groups, alkene groups, amine groups and carboxylic acids. These functional groups are the major classes in many of the chemical groups, which have been previously proven to have potential as reducing agents in the synthesis of silver nanoparticles (Cho et al., 2005). Studies indicate that the carboxyl $(-\mathrm{C}=0)$, hydroxyl $(-\mathrm{OH})$ and amine $(-\mathrm{NH})$ groups in leaf extracts are the ones mainly involved in the fabrication of silver nanoparticles, and for which bands were reported (Vigneshwaran et al., 2007).

Mahesh Kumar et al. (2012) reported that $43 \%$ mortality was noted for first to fourth instars larvae and pupae of Culex quinquefasciatus treated with $S$. xanthocarpum, the $\mathrm{LC}_{50}=155.29,198.32,271.12,377.44$

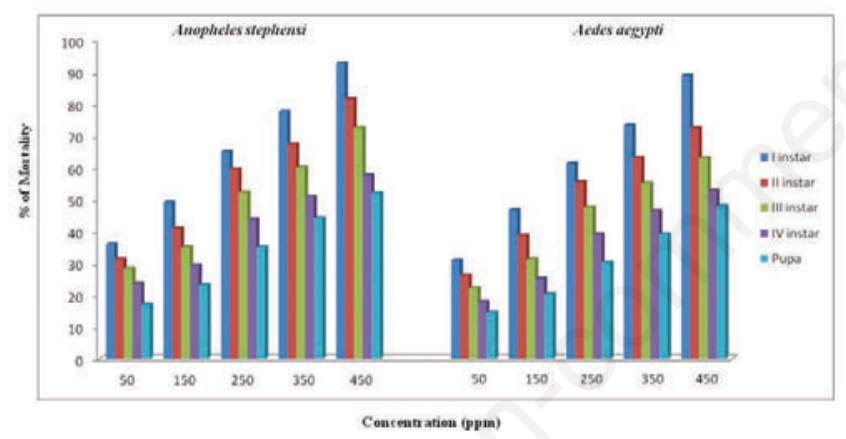

Figure 1. Larvicidal and pupicidal activity of $L$. aspera methanol leaf extract against malarial vector, An. stephensi and dengue vector, Ae. aegypti.

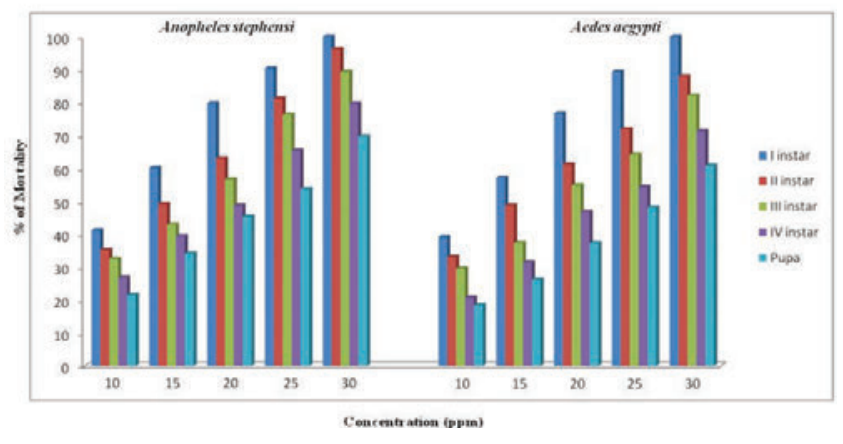

Figure 2. Larvicidal and pupicidal activity of synthesized AgNPs against malarial vector, An. stephensi and dengue vector, Ae. aegypti. and $448.41 \mathrm{ppm}$; the $\mathrm{LC}_{90}=687.14,913.10,1011.89,1058.85$, and 1141.65 ppm, respectively. Results of the present study are consistent with the earlier findings of Muthukrishnan et al. (1997), who observed that the $\mathrm{LC}_{50}$ values of ethyl acetate extract of $L$. aspera were 75.40, 93.09, 132.20 , and $138.60 \mathrm{ppm}$ against the first, second, third, and fourth larval instars, respectively of $C$. quinquefasciatus. Mwangi \& Rembold (1998) reported that the leaf extracts of $L$. aspera exhibited high mortality, especially during the moulting process or the subsequent process of melanization and tanning. Murugan \& Jayabalan (1999) reported that $90 \%$ larval mortality was exhibited at $4 \%$ concentration of the leaf extract of $L$. aspera against the fourth instar larvae of An. stephensi. The ethanolic extract of whole plant $L$. aspera against the first to fourth instar larvae and pupae had $\mathrm{LC}_{50}=9.70,10.27,10.82,11.30$, and 12.73 ppm, respectively, against An. stephensi (Kovendan et al., 2012a). In the present findings, the values for $\mathrm{LC}_{50}$ were $168.41,38.95,309.54,398.16$ and $475.83 \mathrm{ppm}$; the $\mathrm{LC}_{90}$ values were $471.15,653.05,766.25,906.52$ and 991.55 ppm, respectively against An. stephensi.

The larvicidal effect of aqueous crude leaf extracts, silver nitrate solution, and synthesized silver nanoparticles (Ag-NPs) of Mimosa pudica showed that the highest mortality against the larvae of $A$. subpictus was found in synthesized AgNPs $\left(\mathrm{LC}_{50}=8.89,11.82\right.$, and $\left.0.69 \mathrm{ppm}\right)$ and against the larvae of $C$. quinquefasciatus $\left(\mathrm{LC}_{50}=9.51,13.65\right.$, and 1.10 ppm) (Marimuthu et al., 2011). The highest mortality was found in methanol, aqueous, and synthesized AgNPs, which used Nelumbo nucifera plant extract against the larvae of $A$. subpictus $\left(\mathrm{LC}_{50}=8.89,11.82\right.$, and $0.69 \mathrm{ppm} ; \mathrm{LC}_{90}=28.65,36.06$, and $2.15 \mathrm{ppm}$ ) and against the larvae of C. quinquefasciatus $\left(\mathrm{LC}_{50}=9.51,13.65\right.$, and $1.10 \mathrm{ppm} ; \mathrm{LC}_{90}=28.13,35.83$,
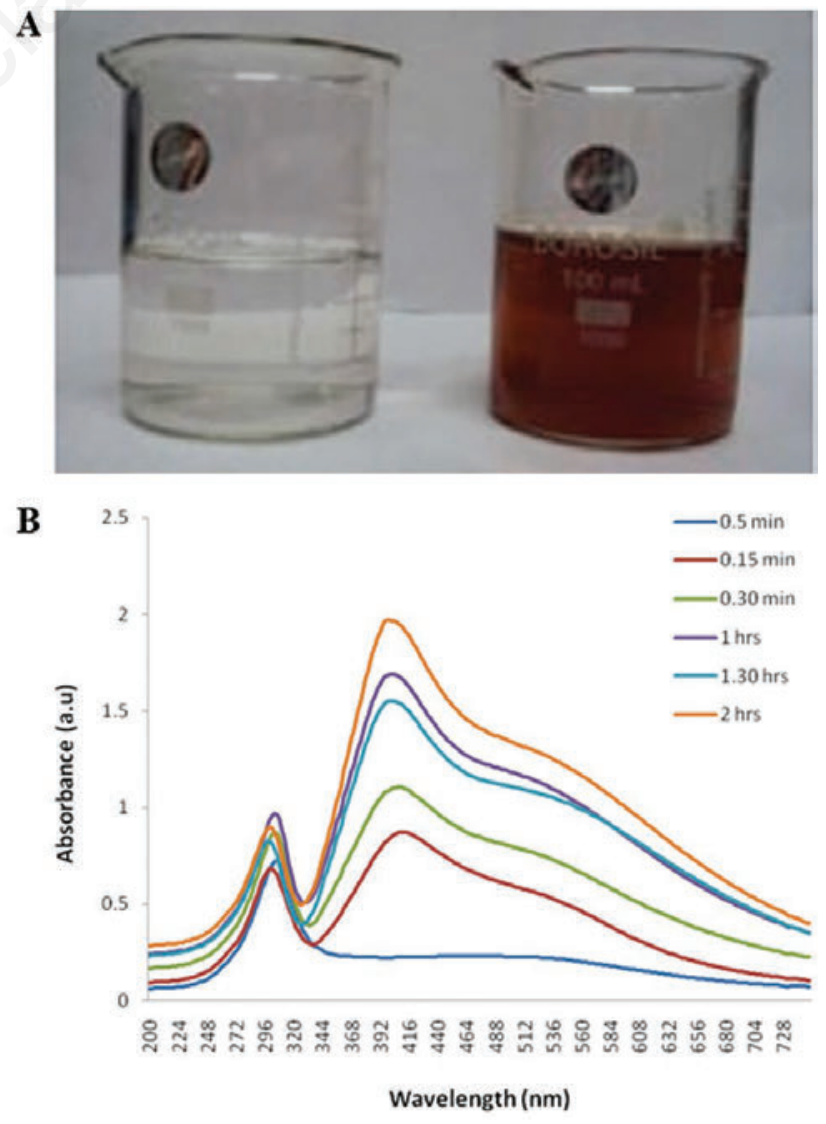

Figure 3. A) Change in colour after adding $\mathrm{AgNO}_{3}$ before and after $30 \mathrm{~min}$ reaction time; B) $\mathrm{UV}$ vis spectra of aqueous silver nitrate with $L$. aspera leaf extract at different time intervals. 
and $3.59 \mathrm{ppm}$ ), respectively (Santhoshkumar et al., 2011). The synthesized zinc oxide nanoparticles showed the $\mathrm{LC}_{50}$ and $\mathrm{r}^{2}$ values against the Rhipicephalus microplus (13.41 mg/L; 0.982), Pediculus humanus capitis $(11.80 ; 0.966 \mathrm{mg} / \mathrm{L})$, and the larvae of $A$. subpictus $(3.19 ; 0.945 \mathrm{mg} / \mathrm{L})$ and C. quinquefasciatus $(4.87 ; 0.970 \mathrm{mg} / \mathrm{L})$, respectively (Kirthi et al., 2011). In the present study, the $\mathrm{LC}_{50}=13.06$, to $25.54 \mathrm{ppm}$; the $\mathrm{LC}_{90}=24.11$, to $47.34 \mathrm{ppm}$, respectively against $A e$. aegypti.
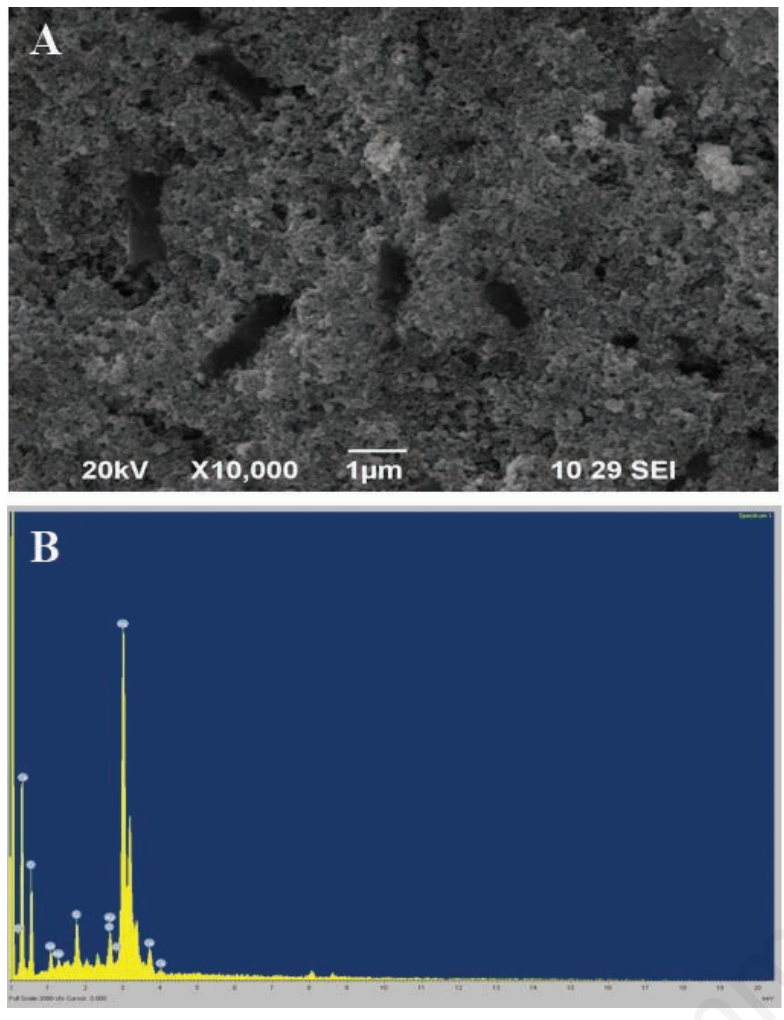

Figure 4. Image of scanning electron microscopic observation of synthesized silver nanoparticles. A) Higher magnification (1 $\mu \mathrm{m})$; B) Energy dispersive X-ray spectroscopy image showing the chemical composition of the particles.

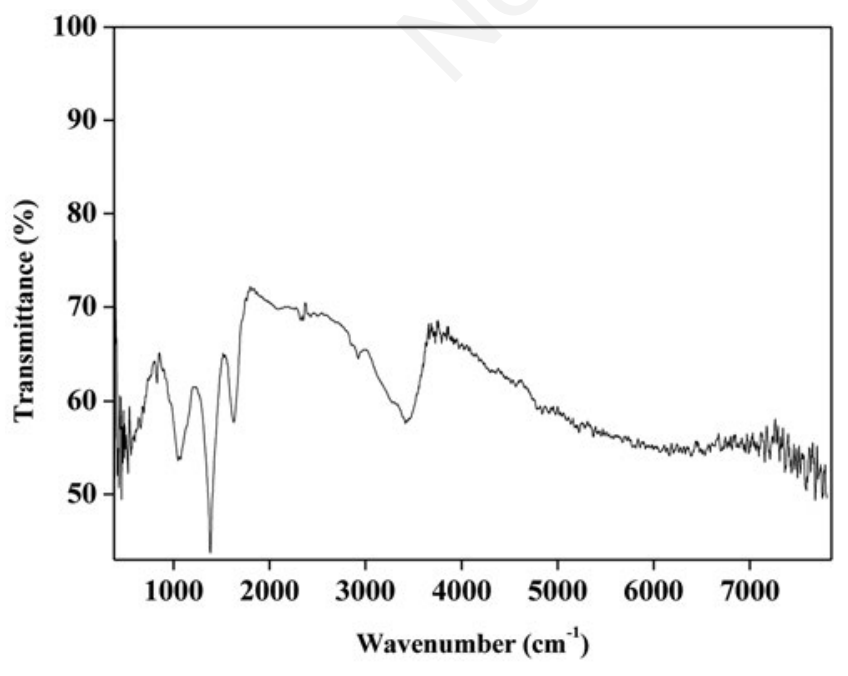

Figure 5. Fourier transformed infra red spectroscopic spectrum of silver nanoparticles synthesized using $L$. aspera leaf extract.
Priyadarshini et al. (2012) have reported on the AgNPs synthesized using Euphorbia hirta plant leaf extract against the malarial vector An. stephensi first to fourth instar larvae and pupae. Their $\mathrm{LC}_{50}$ values were $10.14,16.82,21.51$, and $27.89 \mathrm{ppm}$, for first to fourth instars (respectively), and the $\mathrm{LC}_{90}$ values were $31.98,50.38,60.09$, and $69.94 \mathrm{ppm}$, for first to fourth instars (respectively); the $\mathrm{LC}_{50}$ and $\mathrm{LC}_{90}$ values for pupae were 34.52 and $79.76 \mathrm{ppm}$, respectively. The bioactivity of the latex-producing plant Pergulariadaemia as well as AgNPs against the larval instars of Ae. aegypti and An. stephensi mosquito larvae was determined, the results AgNPs shows excellent larvicidal activity of first, second, third and fourth instars larvae exhibit noticeable effects after 24 or $48 \mathrm{~h}$ of exposure at their $\mathrm{LC}_{50}$ and $\mathrm{LC}_{90}$ values (Patil et al., 2012). Potential antiplasmodial activity of synthesized silver nanoparticles was reported using Andrographis paniculata Nees (Acanthaceae), with inhibitory concentration $\left(\mathrm{IC}_{50}\right.$ ) values of $26 \pm 0.2 \%$ at $25 \mu \mathrm{g} / \mathrm{mL}$, and $83 \pm 0.5 \%$ at $100 \mu \mathrm{g} / \mathrm{mL}$ (Panneerselvam et al., 2011). Synthesis of silver nanoparticles using leaves of Catharanthus roseus Linn. G. Don and their antiplasmodial activities against Plasmodium falciparum have been reported by Ponarulselvam et al. (2012).

In another study, synthesized AgNPs from Murraya koenigii against first to fourth instar larvae and pupae of An. stephensi had $\mathrm{LC}_{50}$ values of $10.82,14.67,19.13,24.35$, and $32.09 \mathrm{ppm}$ and $\mathrm{LC}_{90}$ values of 32.38 , $42.52,53.65,63.51$, and $75.26 \mathrm{ppm}$, respectively (Suganya et al., 2013). Larvicidal studies were carried out against $C$. quinquefasciatus and the results were compared with bulk permethrin. The $\mathrm{LC}_{50}$ of nanopermethrin and bulk permethrin to $C$. quinquefasciatus was 0.117 and 0.715 $\mathrm{mg} / \mathrm{L}$, respectively (Anjali et al., 2010). The mosquito larvicidal activity of UV irradiation-induced AgNPs was found to decrease the survival of fourth instar larvae of Ae. aegypti by $88 \%$ after $24 \mathrm{~h}$ of exposure at $1 \mathrm{ppm}$ concentration. According to Sap-Iam et al. (2010), 5-10 nm polymethacrylic acid capped silver nanoparticles may penetrate the larval membrane, which causes mortality of mosquito larvae.

\section{Conclusions}

In the present investigation, silver nanoparticles were synthesized using $L$. aspera. The synthesized silver nanoparticles were tested for their larvicidal activity against mosquito larvae and pupae of $A n$. stephensi and Ae. aegypti. The prospect of utilising natural products for synthesizing silver nanoparticles and testing their efficacy in controlling mosquitoes larvae is a modern approach facilitating the development of a more potent and environmentally safe biopesticide. This biological reduction of metal could be a boon for the development of clean, nontoxic, and environmentally acceptable control agents. The synthesized silver nanoparticles are hydrophilic in nature, disperse uniformly in water, are highly stable, and exhibit significant mosquito larvicidal and pupicidal activity against An. stephensi and Ae. aegypti as target species in vector control strategies.

\section{References}

ABBOTT W.S., 1925 - A method of computing the effectiveness of insecticides. - J. Ecol. Entomol. 18: 265-267.

AHMAD A., MUKHERJEE P., SENAPATI S., MANDAL D., KHAN M.I., KUMAR, R., SASTRY M., 2003 - Extracellular biosynthesis of silver nanoparticles using the fungus Fusarium oxysporum. - Colloids Surf B. 28: 313.318.

ANJALI C.H., SUDHEERKHAN S., GOSHEN K.M., MAGDASSI S., MUKHERJEE A., CHANDRASEKARAN N., 2010 - Formulation of water-dispersible nanopermethrin for larvicidal applications. Ecotoxicol. Environ. Safety. 73: 1932-1936. 
ASCHER K.R.S., SCHMUTTERER H., ZEBITZ C.P.W., NAQVI S.N.H., 1995 - The Persian lilac or chinaberry tree: Melia azedarach L. In: SCHMUTTERER H (Ed.), The neem tree: source of unique natural products for integrated pest management, medicine, industry and other purposes. - VCH, Weinheim: 605-642.

BEVERIDGE T.J., HUGHES M.N., LEE H., LEUNG K.T., POOLE R.K., SAVVAIDIS I., SILVER S., TREVORS J.T., 1997 - Metal-microbe interactions: contemporary approaches. - Adv. Microbial. Physiol. 38: 178.

BURFIELD T., REEKIE S.L., 2005 - Mosquitoes, malaria and essential oils. - Int. J. Aroma. 15: 30-41.

CHEN L., EVANS J.R., 2009 - Arched structures created by colloidal droplets as they dry. - Langmuir. 25: 11299-11301.

CHO K.H., PARK J.E., OSAKA T., PARK S.G., 2005 - The study of antimicrobial activity and preservative effects of nanosilver ingredient. Electrochim. Acta. 51: 956-960.

DHIMAN C.R., PAHWA S., DHILLON G.P.S., DASH P.A., 2010 - Climate change and threat of vector-borne diseases in India: are we prepared? - Parasitol. Res. 106: 763-773.

FINNEY D.J., 1971 - Probit analysis. - Cambridge University Press, London: 68-78.

GOPALAN S.S., DAS A., 2009 - Household economic impact of an emerging disease in terms of catastrophic out-of-pocket health care expenditure and loss of productivity: investigation of an outbreak of chikungunya in Orissa, India. - J. Vector. Borne. Dis. 46: 57-64.

GOVINDARAJAN M., JEBANESAN A., PUSHPANATHAN T., 2008 Larvicidal and ovicidal activity of Cassia fistula Linn. leaf extract against filarial and malarial vector mosquitoes. - Parasitol. Res.102: 289-292.

HUANG J., LI Q., SUN D., LU Y., SU Y., YANG X., WANG H., WANG Y., SHAO W., HE N., HONG J., CHEN C., 2007 - Biosynthesis of silver and gold nanoparticles by novel sundried Cinnamomum camphora leaf. - Nanotechnol. 18: 1051-04.

JOSEPH T., MORRISON M., 2006 - Nanoforum report: nanotechnology in agriculture and food. Nanoforum.org. Available from: http://www. nanoforum.org/dateien/temp/nanotechnology\%20in\%20agriculture \%20and\%20food.pdf?13062007114636 Accessed: 12/05/07.

KABARU J.M., GICHIA L., 2001 - Insecticidal activity of extract derived from different parts of the mangrove tree Rhizophoramucronata Lam. Against tree arthropods. - Afr. J. Sci. Tech. 2: 44-49.

KIRTHI A.V., RAHUMAN A.A., RAJAKUMAR G., MARIMUTHU S., SANTHOSHKUMAR T., JAYASEELAN C., VELAYUTHAM K., 2011 Acaricidal, pediculocidal and larvicidal activity of synthesized ZnO nanoparticles using wetchemical route against blood feeding parasites. - Parasitol. Res. 109: 461-472.

KRISHNARAJ C., JAGAN E.G., RAJASEKAR S., SELVAKUMAR P., KALAICHELVAN P.T., MOHAN N., 2010 - Synthesis of silver nanoparticles using Acalypha indica leaf extracts and its antibacterial activity against water borne pathogens. - Colloids Surf B. Biointerfaces. 76: 50-56.

KOVENDAN K., MURUGAN K., VINCENT S., BARNARD D.R., 2012a Studies on larvicidal and pupicidal activity of Leucas aspera Willd. (Lamiaceae) and bacterial insecticide, Bacillus sphaericus against malarial vector, Anopheles stephensi Liston. (Diptera: Culicidae). Parasitol. Res. 110: 195-203.

KOVENDAN K., MURUGAN K., SHANTHAKUMAR S.P., VINCENT S., 2012b - Larvicidal activity of Morinda citrifolia L. (Noni) (Family: Rubiaceae) leaf extract against Anopheles stephensi, Culex quinquefasciatus and Aedes aegypti. - Parasitol. Res. 111: 1481-1490.

KOVENDAN K., MURUGAN K., VINCENT S., BARNARD D.R., 2012c Mosquito larvicidal properties of Orthosiphon thymiflorus (Roth) Sleensen. (Labiatae) against mosquito vectors, Anopheles stephensi, Culex quinquefasciatus and Aedes aegypti (Diptera: Culicidae). Asian. Pac. J. Trop. Med.: 412-420.

KOVENDAN K., MURUGAN K., VINCENT S., 2012d - Mosquitocidal effi- cacy of Orthosiphon thymiflorus (Roth) sleesen. (Family: Labiatae) leaf extract and microbial insecticide, Metarhizium anisopliae against dengue vector, Aedes aegypti (Diptera: Culicidae). Diversity Physiol. Proces.: 137-151.

KUMAR V., YADAV S.K., 2009 - Plant-mediated synthesis of silver and gold nanoparticles and their applications. - J. Chem.Techno.l Biotechnol. 84: 151-157.

KUMAR A., VALECHA N., JAIN T., ADITYA P., 2007 - Dash burden of malaria in India: retrospective and prospective view. - Am. J. Trop. Med. Hyg. 77: 69-78.

LIU X.Y., DU N., 2004 - Zero-sized effect of nano-particles and inverse homogeneous nucleation. - J. Biol. Chem. 279: 6124-6131.

MAHESWARAN R., SATHIS S., IGNACIMUTHU S., 2008 - Larvicidal activity of Leucus aspera (Willd.) against the larvae of Culex quinquefasciatus Say. and Aedes aegypti L.- Int. J. Int. Biol. 2: 214-217.

MAHESH KUMAR P., MURUGAN K., KOVENDAN K., SUBRAMANIAM J., AMERASAN D., 2012 - Mosquito larvicidal and pupicidal efficacy of Solanum xanthocarpum (Family: Solanaceae) leaf extract and bacterial insecticide, Bacillus thuringiensis, against Culex quinquefasciatus Say (Diptera: Culicidae). - Parasitol. Res. 110: 2541-2550.

MARIMUTHU S., RAHUMAN A.A., RAJAKUMAR G., SANTHOSHKUMAR T., KIRTHI A.V., JAYASEELAN C., BAGAVAN A., ZAHIR A.A., ELANGO G., KAMARAJ C., 2011 - Evaluation of green synthesized silver nanoparticles against parasites. - Parasitol. Res. 10: 2212-2224.

MITTAL P.K., ADAK T., SUBBARAO S.K., 2005 - Inheritance of resistance to Bacillus sphaericus toxins in a laboratory selected strain of Anopheles stephensi (Diptera: Culicidae) and its response to Bacillus thuringiensis var. israelensis. - Curr. Sci. 89: 442-443.

MURUGAN K., JEYABALAN D., 1999 - Effect of certain plant extracts against the mosquito, Anopheles stephensi Liston. - Curr. Sci. 76: 631-633.

MUTHUKRISHNAN J., PUSPHALATHA H., KASTHURIBHAI A., 1997 Biological effects of four plant extracts on Culex quinquefasciatus Say. - Insect. Sci. Appl. 17: 389-394.

MWANGI R.W., REMBOLD H., 1998 - Growth inhibiting and larvicidal effects of Melia volkensii extracts on Aedes aegypti larvae. Entomol. Exp. Appl. 46: 103-108.

NATARAJAN K., SELVARAJ S., MURTY V.R., 2010 - Microbial production of silver nanoparticle. - Digest. J. Nanomat. Biostruct. 5: 135-140.

PATIL C.D., BORASE H.P., PATIL S.V., SALUNKHE R.B., SALUNKE B.K., 2012 - Larvicidal activ-ity of silver nanoparticles synthesized using Pergularia daemia plant latex against Aedes aegypti and Anopheles stephensi and non-target fish Poecillia reticulata. - Parasitol. Res. 111: 555-560.

PANNEERSELVAM C., PONARULSELVAM S., MURUGAN K., 2011 Potential anti-plasmodial activity of synthesized silver nanoparticle using Andrographis paniculata Nees (Acanthaceae). - Arch. Appl. Sci. Res. 3: 208-217.

PONARULSELVAM S., PANNEERSELVAM C., MURUGAN K., AARTHI A., KALIMUTHU K., THANGAMANI S., 2012 - Synthesis of silver nanoparticles using leaves of Catharanthus roseus Linn. G. Don and their anti-plasmodial activities. - Asian-Pacific. J. Trop. Biomed. 574-580.

PRIYADARSHINI K.A., MURUGAN K., PANNEERSELVAM C., PONARULSELVAM S., HWANG J.S., NICOLETTI M., 2012 - Biolarvicidal and pupicidal potential of silver nanoparticles synthesized using Euphorbia hirta against Anopheles stephensi Liston (Diptera: Culicidae). - Parasitol. Res. 111: 997-1006.

SADHU S.K., OKUYAMA E., FUJIMOTO H., ISHIBASHI M., 2003 Separation of Leucus aspera, a medicinal plant of Bangladesh, guided by prostaglandin inhibitory and antioxidant activities. - Chem. Pharm. Bull. (Tokyo) 51: 595-598.

SANTHOSHKUMAR T., RAHUMAN A.A., RAJAKUMAR G., MARIMUTHU S., BAGAVAN A., JAYASEELAN C., ZAHIR A.A., ELANGO G., KAMA- 
RAJ C., 2011 - Synthesis of silver nanoparticles using Nelumbo nucifera leaf extract and its larvicidal activity against malaria and filariasis vectors. - Parasitol. Res. 108: 693-702.

SAP-IAM N., HOMKLINCHAN C., LARPUDOMLERT R., WARISNOICHAROEN W., SEREEMASPUN A., DUBAS S.T., 2010 - UV irradiation induced silver nanoparticles as mosquito larvicides. - J. Applied. Sci. 10: 3132-3136.

SCOTT N.R., 2007 - Nanotechnology opportunities in agriculture and food systems. Biological \& Environmental Engineering, Cornell University NSF Nanoscale Science \& Engineering Grantees Conference Arlington, VA.

SCRINIS G., LYONS K., 2007 - The emerging nano-corporate paradigm: nanotechnology and the transformation of nature, food and Agrifood systems. - Int. J. Sociol. Food. Agric. 15: 1-23.

SHANKAR S.S., RAI A., ANKAMWAR B., SINGH A., AHMAD A., SASTRY M., 2004 - Biological synthesis of triangular gold nanoprisms. - Nat. Mater. 3: 482-488.

SHARMA S.K., UPADHYAY A.K., HAQUE M.A., TYAGI P.K., RAGHAVENDRA K., DASH A.P., 2010 - Wash-resistance and field evaluation of alphacypermethrin treated long-lasting insecticidal net (Interceptor) against malaria vectors Anopheles culicifacies and Anopheles fluviatilis in a tribal area of Orissa, India. - Acta. Tropica. 116: 24-30.

SHRIVASTAVA S., DASH D., 2010 - Label-free colorimetric estimation of proteins using nanoparticles of silver. - Nano-Micro. Lett. 2: 164-168.
SNOW R.W., GUERRA C.A., NOOR A.M., MYINT H.Y., HAY S.I., 2005 The global distribution of clinical episodes of Plasmodium falciparum malaria. - Nature. 434: 214-217.

SRINIVASAN R., RAVAL B., SUVARCHALA A., HONEY A., TEJASWINI A., NEERAJA P., 2011 - Leucas aspera - Medicial plant: a review. - Int. J. Pharma. Biosci. 2: 153-159.

STUART B.H., 2002 - Polymer analysis. - John Wiley \& Sons, UK.

SUGANYA S., MURUGAN K., KOVENDAN K., MAHESH KUMAR P., HWANG J.S., 2013 - Green synthesis of silver nanoparticles using Murraya koenigii leaf extract against Anopheles stephensi and Aedes aegypti. - Parasitol. Res. 112: 1385-1397.

VIGNESHWARAN N., ASHTAPUTRE N.M., VARADARAJAN P.V., NACHANE R.P., PARALIKAR K.M., BALASUBRAMANYA R.H., 2007 Biological synthesis of silver nanoparticles using the fungus, Aspergillus flavus. - Mater. Lett. 66: 1413-1418.

WHO, 1999 - Prevention and control of dengue and DHF. WHO-SEARO Regional Publication 29. - World Health Organization, Geneva.

WHO, 2007 - Global plan to combat neglected tropical diseases 2008-2015. WHO/CDS/NTD/2007.40. - World Health Organization, Geneva.

WHO, 2010 - World malaria report, India. - World Health Organization, Geneva. Available from: http://www.who.int/malaria/publications/ country-profiles/profile_ind_en.pdf

XU H., KÄLL M., 2002 - Morphology effects on the optical properties of silver nanoparticles. - J. NanoNanotech. 4: 254-259. 